\title{
The Realized Yield Effect of Genetically Engineered Crops: U.S. Maize and Soybean
}

\author{
Zheng Xu, David A. Hennessy, Kavita Sardana, and GianCarlo Moschini`
}

\begin{abstract}
Yield improvements are critical to ensuring food security for a growing world population especially in view of the increasing potential for use of land in biofuel production. Efforts to sustain the impressive rate of past productivity gains, epitomized by such successes as the Green Revolution, are bound to rely on biotechnology innovations such as those responsible for the development of genetically engineered (GE) crops. Some argue that the use of biotechnology can substantially improve yields relative to the trajectory established by traditional breeding in the 20th century. Because U.S. adoption of GE varieties has been very strong since their introduction in the late 1990s, we investigated empirically whether and to what extent the GE technology has improved realized yields. We study this question for nonirrigated U.S. maize (Zea mays L.) and soybean [Glycine max (L.) Merr.] yields over 1964 through 2010, having controlled for local effects, weather, fertilization, and the preexisting (non-GE) crop improvement trend. For maize we find that GE varieties have increased realized yields, with a stronger gain in the Central Corn Belt (CCB). For soybeans, GE varieties appear to have slightly reduced yields. For both crops we find a strong trend in yield growth, which may have accelerated in recent years within the CCB. However, the combined effects of yield trend and GE adoption are predicted to fall short of the growth rate envisioned by industry projections.
\end{abstract}

Z. Xu, Dep. of Genetics, Univ. of North Carolina at Chapel Hill, Chapel Hill, NC 27599; D.A. Hennessy and G. Moschini, Dep. of Economics, Iowa State Univ., Ames, IA 50011; K. Sardana, Dep. of Policy Studies, TERI Univ., New Delhi, 110 070, India. Received 30 June 2012. `Corresponding author (moschini@iastate.edu).

Abbreviations: $\mathrm{CCB}$, Central Corn Belt; GE, genetically engineered; OLS, ordinary least squares; R\&D, research and development; USDA, United States Department of Agriculture.

$\mathrm{T}$ HE ADVENT of large scale cultivation of genetically engineered (GE) varieties has been one of the dominant features of innovation in agriculture over the last $15 \mathrm{yr}$ (Moschini, 2008). Introduced in the late 1990s in some major crops [chiefly soybean and maize but also cotton (Gossypium hirsutum L.) and canola (Brassica napus L.)], GE varietal traits have been rapidly adopted in several countries. In 2011 they were grown on 160 million ha worldwide (James, 2011), 90\% of which was accounted for by five countries: United States, Brazil, Argentina, India, and Canada. In the United States, GE varieties have displayed historically unprecedented adoption rates: by 2012, 88\% of the maize crop and $93 \%$ of the soybean crop were accounted for by GE varieties (Fernandez-Cornejo, 2012), and the pace of adoption (Fig. 1) has been as fast as that of the celebrated hybrid maize success story (Griliches, 1960). The GE technology has also generated controversy worldwide (Charles, 2002; Miller and Conko, 2004), and large blocks of countries (most notably the European Union) are still not open to its unconstrained use. Notwithstanding, the GE technology innovativeness, vis-à-vis traditional crop breeding, is held by many as the more likely way to emulate past successes such as hybrid maize and the Green Revolution (Fedoroff et al., 2010).

Published in Crop Sci. 53:735-745 (2013).

doi: 10.2135/cropsci2012.06.0399

(C) Crop Science Society of America | 5585 Guilford Rd., Madison, WI 53711 USA

All rights reserved. No part of this periodical may be reproduced or transmitted in any form or by any means, electronic or mechanical, including photocopying, recording, or any information storage and retrieval system, without permission in writing from the publisher. Permission for printing and for reprinting the material contained herein has been obtained by the publisher. 


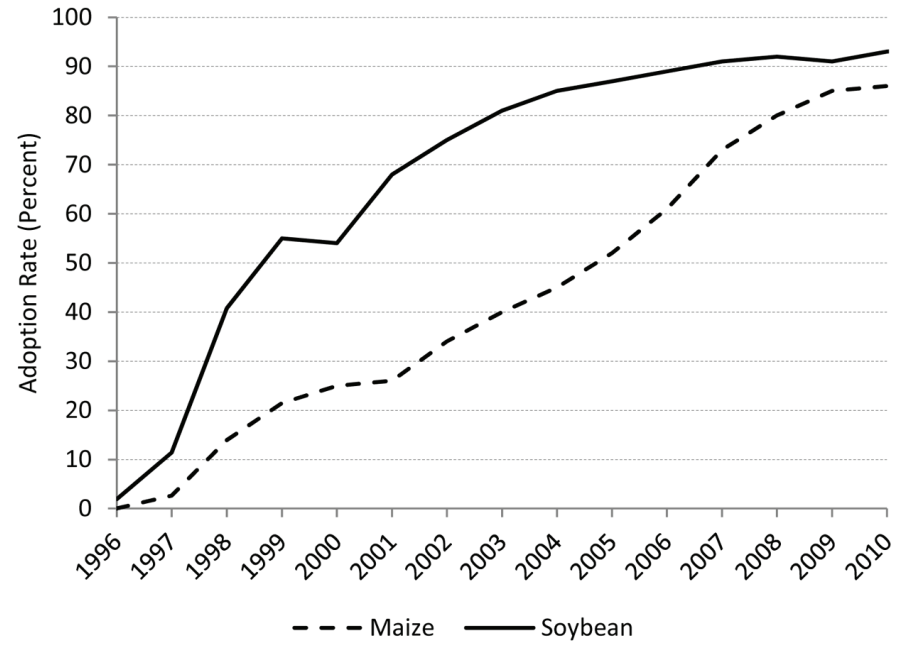

Figure 1. Percent adoption of maize and soybean genetically engineered varieties (all traits) in the United States from 1996 through 2010. Data for 2000 through 2010 are from the USDA, obtained from a randomized survey conducted annually. The USDA did not survey before 2000. For 1996 through 1999, Monsanto's U.S. adoption estimates are used to complete the USDA data set in a consistent fashion.

Genetically engineered varieties commercialized to date have emphasized insect resistance, herbicide tolerance, and stacked traits that combine these attributes (Herdt and Nelson, 2011). Beyond their direct effects on chemical input needs, these traits have reduced labor, management, machinery, and energy use in crop production while increasing operational flexibility (Huang et al., 2005). Whereas such cost-saving considerations alone can rationalize farmers' adoption, GE varieties may have affected yields as well (Park et al., 2011). The embedded plant protection traits can be more effective in protecting potential yield than the chemicals they replaced (GómezBarbero et al., 2008; Ma et al., 2009). Indeed it may well be that the extent of pesticide provided in the seed exceeds the amount of protection that the grower would have bought in the input market were the pesticide trait unavailable, suggesting that yield would increase as a result of greater overall protection. Growers may apply higher levels of other inputs in response to the new technologies. Also, additional operational flexibility during planting may contribute to reducing weather-related yield losses (Egli and Cornelius, 2009; Fischer et al., 2009) while pest-controlling GE varieties (e.g., Bt maize) provide a positive externality for local nonadopters (Wu et al., 2008; Hutchison et al., 2010; Lu et al., 2012). Plot data from commercial corn breeding programs suggest that GE insect resistant traits in maize increase mean yield by increasing yield when it would otherwise be low (Edgerton et al., 2012), that is, the seeds reduce yield risk.

Yield improvements are critical to the challenges of food security (Fischer et al., 2009; Tilman et al., 2011). The Food and Agricultural Organization estimates that about
850 million of the world's population are undernourished (FAO, 2011). Ultimately, the resolution of this longstanding problem hinges on the balance between the rates of growth in demand and supply of food. Demand for food will continue to rise in the next few decades because of expected growth in world population, which is projected by the United Nations to reach 9.3 billion in 2050 from the current level of about 7 billion (United Nations, 2011), and because of income growth among many developing and newly industrialized economies. Given the constraints on the global availability of cropland, the single most important element affecting food supply growth is land yield productivity. The importance of agricultural productivity for food security is heightened by climate change concerns and by the recent trend toward increasing the allocation of land to potential biofuel production (Tilman et al., 2009; Runge and Senauer, 2007; Hertel, 2011). This shift toward biofuel production is contributing to existing worries about the rising level and volatility of commodity prices (FAO, 2011; Wright, 2011) as well as worries about water availability (Dominguez-Faus et al., 2009).

There is no doubt that GE varieties - and biotechnology more generally_can help sustain the continued improvements in agricultural productivity needed for global food security. An unresolved and important question, however, concerns what can be rationally expected on this front. Some have discussed an apparent slowdown of grain yield growth (Alston et al., 2009). Others claim that biotechnology can enhance yields dramatically, suggesting that U.S. maize average yields can be doubled over the next two decades (Edgerton, 2009). Are these yield expectations realistic? Because such productivity improvements are to be enabled by new biotechnology breeding tools, is this scenario consistent with the evidence on realized (farmlevel) yields of GE varieties to date?

Existing studies are inconclusive on these questions. Studies that have emphasized the impact of temperature and precipitation on U.S. yields (Schlenker and Roberts, 2009; Tannura et al., 2008) or the impact of climate change on crop yields worldwide (Lobell et al., 2011) do not explicitly address possible GE effects. Yield enhancements due to GE varieties in specific settings have been reported for Bt maize in Spain (Gómez-Barbero et al., 2008) and Argentina (Qaim and de Janvry, 2005) and for Bt cotton in India (Qaim and Zilberman, 2003). Based on trial data in China, yield increases from Bt rice (Oryza sativa L.) adoption are foreseen (Huang et al., 2008). Even so, a literature overview on GE yield impacts in the United States claims no positive effects (Gurian-Sherman, 2009).

This study aims to isolate the impact of GE crop adoption on U.S. maize and soybean yields from other possible confounding effects. The focus is on realized yield (as opposed to field trials), specifically historical U.S. countylevel average yields for maize and soybean. The model that 
we estimate presumes that realized yields are determined by (i) state of technology (e.g., germplasm quality of commercialized varieties) available at time $t$, (ii) regional differences in state of technology available at time $t$, (iii) rate of adoption of GE varieties, (iv) weather experienced during the growing season, in terms of both temperature and water stress metrics, (v) amount of fertilizer applied, and (vi) other county-specific factors that affect productivity (e.g., soil quality). Factors (i) through (vi) vary considerably over time and space, and this variability is used to identify the yield responses of interest. Our main objectives are to assess the impacts of technology and rate of adoption having controlled for all other relevant factors as well as possible. But because our model controls for weather and $\mathrm{N}$ application rates, the analysis also provides evidence of weather and fertilization effects as well as findings on differential impacts by region.

\section{MATERIALS AND METHODS}

The data we have assembled for the analysis constitutes a typical time-series-cross-section (i.e., "panel") data set in which the unit of analysis is the county level. The variable to be explained, $y_{i, t}$, is the average yield for county $i$ in year $t$ as reported by the National Agricultural Statistics Service of the U.S. Department of Agriculture (USDA). The data cover the period 1964 through 2010 for a large set of counties (to be defined below). This 47-yr span includes the entire GE period (post-1996) and a long stretch of pre-GE data, and it is therefore suitable to investigate the question of the possible realized yield effect of GE varieties. One of the reasons for choosing 1964 as the initial year of the sample is that this is the first year for which the USDA provides state-level, crop-specific fertilization data. Explanatory variables, taken as predetermined with respect to yield realizations, are chosen so as to account for all of the main determinants of realized yields. The approach taken is based on the statistical yield model popularized by Thompson $(1969,1975)$.

Plant growth occurs only within a well-defined temperature range, with recognized threshold effects. Whether a given amount of heat is incident today or a week from now should matter less than if the time gap were a month or more. For these reasons we use two temperature metrics, each calculated separately for each month of the growing season: growing degree days, $G_{i, m, t}$, and excess heat degree days, $E_{i, m, t}$ (for county $i$; month $m$ in set $M$, in which $M \equiv$ \{May, June, July, August, September $\}$; and year $t=[1964, \ldots, 2010])$. Because soils can store moisture (a stock variable), water stress affecting yields is measured by the Palmer $Z$ index, $Z_{i, m, t}$ (Palmer, 1965).

Unlike other yield studies we control for the impact of $\mathrm{N}$ use $N_{[i], t}\left(\mathrm{~kg} \mathrm{ha}^{-1}\right)$, a recognized major contributor to yield gains in the 20 th century (Smil, 2004). Here square brackets for the county indicator $i$ are used to denote the fact that the $\mathrm{N}$ data we use is at the state level of aggregation. The GE adoption rate $A_{[i], t}$ can have values on $[0,1]$ and denotes, for each crop, the fraction of planted hectares for county $i$ in year $t$ that is accounted for by GE varieties. As in other studies, a trend variable $T_{t}$ captures changes in mean yields over time for reasons not otherwise modeled (e.g., germplasm improvement via traditional breeding). The results reported rely on the standard (linear) trend $T_{t}=1,2, \ldots, 47$.
A working hypothesis is that trend and GE yield responses differ between the center and the periphery of U.S. growing regions. We identify the three-state region of Iowa, Illinois, and Indiana-henceforth referred to as the Central Corn Belt (CCB) - as the core region for maize and soybeans. These three states accounted for $41.6 \%$ of U.S. corn-for-grain production and $36.7 \%$ of soybean-for-beans production in 2011 (USDANASS, 2012). Breakthrough innovations are likely targeted at such core regions before being applied elsewhere. For example, U.S. hybrid maize adoption rates were lower outside the CCB, even 25 yr after commercialization (Griliches, 1960). Indeed, dominant seed companies have located the large majority of their midwestern research facilities in these three CCB states.

Conditional on modeling the underlying technological progress by a linear trend, two alternative GE adoption yield effects are considered. In what is labeled the "shift model" the yield function shifts in proportion to the adoption rate but independent of time. In the alternative specification, labeled the "slope model," it is the yield response to trend that changes in proportion to adoption. Letting $y_{i, t}$ denote yield realizations for county $i$ in year $t$, setting $R_{i}=1$ whenever county $i$ is in the CCB $\left(R_{i}=0\right.$ otherwise), and given the variables defined in the foregoing, the regression equation for the shift effect model is

$$
\begin{aligned}
y_{i, t} & =\alpha_{i}+W_{i, t}+\beta_{N} N_{[i], t}+\beta_{T} T_{t}+\beta_{R T} R_{i} T_{t}+\beta_{A} A_{[i], t} \\
& +\beta_{A R} A_{[i], t} R_{i}+\varepsilon_{i, t},
\end{aligned}
$$

in which $W_{i, t}$ denotes the weather variables, represented by

$$
W_{i, t} \equiv \sum_{m \in M}\left(\beta_{G m} G_{i, m, t}+\beta_{E m} E_{i, m, t}+\beta_{Z m} Z_{i, m, t}+\beta_{Z Z m} Z_{i, m, t}^{2}\right),
$$

with quadratic terms included to capture possible nonlinearities in the response to water stress. Error term $\varepsilon_{i, t}$ is assumed to be identically and independently distributed, and the betas are parameters to be estimated. The regression equation for the alternative slope effect model is

$$
\begin{aligned}
& y_{i, t}=\alpha_{i}+W_{i, t}+\beta_{N} N_{[i], t}+\beta_{T} T_{t}+\beta_{R T} R_{i} T_{t} \\
& \quad+\beta_{A T} A_{[i], t}\left(T_{t}-\tau\right)+\beta_{A R T} A_{[i], t} R_{i}\left(T_{t}-\tau\right)+\varepsilon_{i, t},
\end{aligned}
$$

in which $\tau$ is the number of years into our data set that GE seed for a crop was first planted. Because GE varieties were first planted in 1996 for soybean and in 1997 for maize, then $\tau=32$ for soybeans and $\tau=33$ for maize (recall that $T_{t}=1$ in 1964).

Again, the objective is to isolate the impact of GE crop adoption on U.S. maize and soybean yields from other possible confounding effects. There may be factors other than those modeled explicitly that affect yield realizations, of course. If such factors can be presumed to be county-specific and largely unchanged over time (e.g., soil quality, drainage infrastructure), then they are fully accounted for by the estimation procedure used (by a county-specific intercept $\alpha_{i}$ ). While some of the factors that data availability do not allow us to account for will change over time, we expect that they will vary slowly and these factor variations will be subsumed into the model's error term $\varepsilon_{i, t}$. All data used are from publicly available sources. More details on the variables and data used are provided next.

\section{Heat Variables}

Daily temperature data are used to calculate monthly growing degree days and overheating degree days at the county level. Daily maximum $\left(C_{i, m, t, d}^{\max }\right)$ and minimum $\left(C_{i, m, t, d}^{\min }\right)$ temperatures $\left({ }^{\circ} \mathrm{C}\right)$ 
were obtained for weather stations nearest to the geographic center of the county of interest, as extracted from the U.S. Historical Climatology Network of 1218 weather stations in the 48 contiguous states. For these calculations, we merged 1218 data files each for a separate weather station and then extracted $C_{i, m, t, d}^{\max }$ and $C_{i, m, t, d}^{\min }$

Heat variables studied were based on daily growing degrees $G_{i, m, t, d}$ and excess heat degrees $E_{i, m, t, d}$ calculated for county $i$, month $m \in M$, year $t$, and day of month $d$. Growing degree days for a given day are calculated as 10 less than the average of $\min \left[\max \left[C_{i, m, t, d}^{\max }, 10\right], 30\right]$ and $\min \left[\max \left[C_{i, m, t, d}^{\min }, 10\right], 30\right]$. Excess heat degree days for a given day are calculated as 32.22 less than the average of $\max \left[C_{i, m, t, d}^{\max }, 32.22\right]$ and $\max \left[C_{i, m, t, d}^{\min }, 32.22\right]$. Thus, $G_{i, m, t, d}$ counts additional beneficial degrees only in range $[10,30]$ (Neild and Newman, 1990), and $E_{i, m, t, d}$ counts additional harmful degrees only for temperatures greater than $32.22^{\circ} \mathrm{C}$ (Schlenker and Roberts, 2009).

Both are then summed over the days in each month $m \in M$ at each weather station. A county's monthly growing $G_{i, m, t}$ and excess heat $E_{i, m, t}$ degree days are approximated by their respective values for the weather station nearest to the county's geographic center. The computed temperature indices $G_{i, m, t}$ and $E_{i, m, t}$ display considerable time and cross-section variation, which will be helpful in identifying the responses of interest. As an illustration, panels A and B of Fig. 2 report the summary distribution of the July $G_{i, m, t}$ and $E_{i, m, t}$ (specifically the mean and the 5 and 95\% percentile points for each year), across all counties in the sample.

\section{Water Stress}

Water stress is measured by the Palmer $Z$ index $Z_{i, m, t}$ for each month $m \in M$. The monthly Palmer's $Z$ value is a measure of the departure from normal of the moisture availability for that month (Heim, 2002). Although crops differ in water needs, the index is not conditioned by crop. A value of 0 is to be expected and -2 or less represents drought conditions while +5 or more represents flood conditions. Data were obtained directly from the U.S. Department of Commerce National Climate Data Center (http://www.drought.noaa.gov/palmer.html, accessed 29 June 2012). Data are for climate divisions within a state. There are 344 climate divisions within the contiguous United States, each covering about 10 counties. As water stress depends on precipitation and temperature, both are used in this index's calculation.

The index is standardized to local climate to calculate dryness relative to local norms. This is appropriate as production choices are conditioned on local dryness norms so that deviation from norms should matter most when determining deviation from trend yield. Soil attributes matter when determining a crop's capacity to deal with water availability anomalies, and the attributes are accounted for in index parameters, but index calculations are spatially aggregated. Data were processed using ArcMap (ESRI, 2011). Counties within the same state division are assigned the same Palmer's $Z$ index. To illustrate the time and cross-section variability of the Palmer $\mathrm{Z}$ index in our data, panel C of Fig. 2 reports the summary distribution of the July $Z_{i, m, t}$ across all counties in the sample.

\section{Nitrogen}

The second half of the 20th century has seen extensive growth in use of artificial fertilizer (Gardner, 2002, p. 22-24). The need for applied $\mathrm{N}$ in maize production is well recognized. Biological fixation meets much of a soybean plant's $N$ requirements. Salvagiotti et al. (2008) review the literature to conclude that biological fixation does not meet all crop needs where the yield benefits from applied $\mathrm{N}$ is greatest in high yield environments. Although the gap between needs and biological fixation may be greatest during the seed-fill stage, surface application may inhibit fixation and preplant subsurface application of controlled-release $\mathrm{CH}_{4} \mathrm{~N}_{2} \mathrm{O}$ (urea) may be the preferred strategy (Salvagiotti et al., 2009).

Unlike other yield studies (e.g., Tannura et al., 2008; Schlenker and Roberts, 2009), this report controls for fertilizer (N) use. State-level $\mathrm{N}$ data for corn and also for soybeans were obtained from the USDA (USDA Economic Research Service, 2011b). The average $\mathrm{N}$ application rate on U.S. maize has increased from $55 \mathrm{~kg} \mathrm{ha}^{-1}$ in 1964 to its peak of $152 \mathrm{~kg} \mathrm{ha}^{-1}$ in 1985 and has leveled off since (average of $144 \mathrm{~kg} \mathrm{ha}^{-1}$ over the period 19862010). For soybean, when averaged across farms that do and do not apply, the average $\mathrm{N}$ application rate has increased from 1.1 $\mathrm{kg} \mathrm{ha}^{-1}$ in 1964 to its peak of $6.6 \mathrm{~kg} \mathrm{ha}^{-1}$ in 2005 but has declined since. Accounting for this evolution is necessary to avoid biased estimates of other technology effects. The available USDA data have many missing observations at the state level, especially over the period 2004 through 2009. To fill in for state-level missing values, we calculate the U.S.-level $\mathrm{N}$ use rate for both crops for all years. State-level $\mathrm{N}$ use rate missing values are filled in for all counties in the sample by using the predicted values of a zerointercept ordinary least squares (OLS) regression of state-level $\mathrm{N}$ use on U.S.-level $\mathrm{N}$ use.

\section{Genetically Engineered Adoption}

Genetically engineered adoption rate $A_{[i], t} \in[0,1]$ is the fraction of planted acreage that uses varieties with GE traits (single trait or stacked traits) for the state of county $i$ in year $t$ (as noted earlier, GE adoption data are available only at the state level). Data are for adoption across all GE traits. Data from 2000 through 2010 are from the USDA (USDA Economic Research Service, 2011a) and are obtained from a randomized survey conducted each June concerning biotechnology varieties sown that year. The USDA did not survey before 2000. However, Monsanto Company has made public its estimates of U.S.-wide adoption, including for all biotechnology varieties, over 1996 through 2010, with GE cultivation commencing in 1996 for soybeans and in 1997 for maize. We have spliced Monsanto's data into the USDA adoption data to obtain a consistent dataset.

\section{Counties Studied}

The counties included in the sample satisfy the following three qualifications. First, we use only counties where less than $10 \%$ of harvested cropland is irrigated (according to the 2002 U.S. Census of Agriculture [USDA-NASS, 2004]). Year 2002 was chosen as a compromise between the better quality information available in more recent years and matching the time point with the temporal center of the time series under scrutiny. The nature of production on irrigated cropland is very different from that on rainfed cropland and especially so in regard to response to weather variables. Any endeavor to account for both types of production in one model would likely result in model misspecification. Yield data are not available for all counties for all 
years. To ensure representativeness of the sample, only counties with data available for at least two-thirds of the pre-GE years and two-thirds of the post-GE years (e.g., pre- and post-1996 for soybean) were included. Finally, counties with incomplete Palmer's $\mathrm{Z}$ index time series were excluded (only four counties that survived the first two requirements failed the third). For maize our final sample encompasses 1350 counties in 33 states (1063 in 30 states for soybean). These counties accounted for $81 \%$ of U.S. production in 2010 (78\% for soybean). Given the $47-y r$ span of the data and after accounting for the few missing observations, the sample used in estimation comprises 61,821 county-yield observations for maize (47,693 for soybean). Figure 3 illustrates the distribution of counties.

\section{On the Regional Effects Hypothesis}

In his pioneering work on hybrid corn adoption Griliches (1960, p. 275) states: "The actual process of developing superior hybrids had to be performed separately for each locality. ...Although superior hybrids became available in the Corn Belt in the early 1930s, it was only in the middle of the 1940s that good hybrids began to appear in the South." Because seed companies continue to develop and market varieties well suited to an area's soils and climate, it is of interest to see where they locate their main production facilities. Monsanto and Dupont (through Dupont Pioneer Hi-Bred) dominate U.S. maize and soybean seed markets (Moschini, 2010). According to its 2011 annual report (form 10-K), Monsanto spent US $\$ 1.386$ billion on in-firm research and development (R\&D) in 2011, largely on seed traits (Monsanto Company, 2011). According to its 2011 databook (DuPont Company, 2012), seed constitutes 68\% of Dupont's Agriculture and Nutrition division's sales while R\&D expenditure on "feeding the world" amounted to $\$ 1.24$ billion in 2011. Monsanto and Dupont Pioneer websites (Monsanto Company, 2012; E. I. du Pont de Nemours and Company, 2012) confirm that the location of their major U.S. facilities favors the CCB. Specifically, with reference to the maize and soybean growing area covered by this study, for both companies we find that $55 \%$ of their major facilities are located in the three states of Iowa, Illinois, and Indiana. Hence, we conjecture that trend yield growth is higher in CCB than elsewhere.

\section{Estimation Procedure}

The shift model that we estimate is reported in Eq. [1] above, in which $t=1,2, \ldots, 47$ denotes years and $i$
A

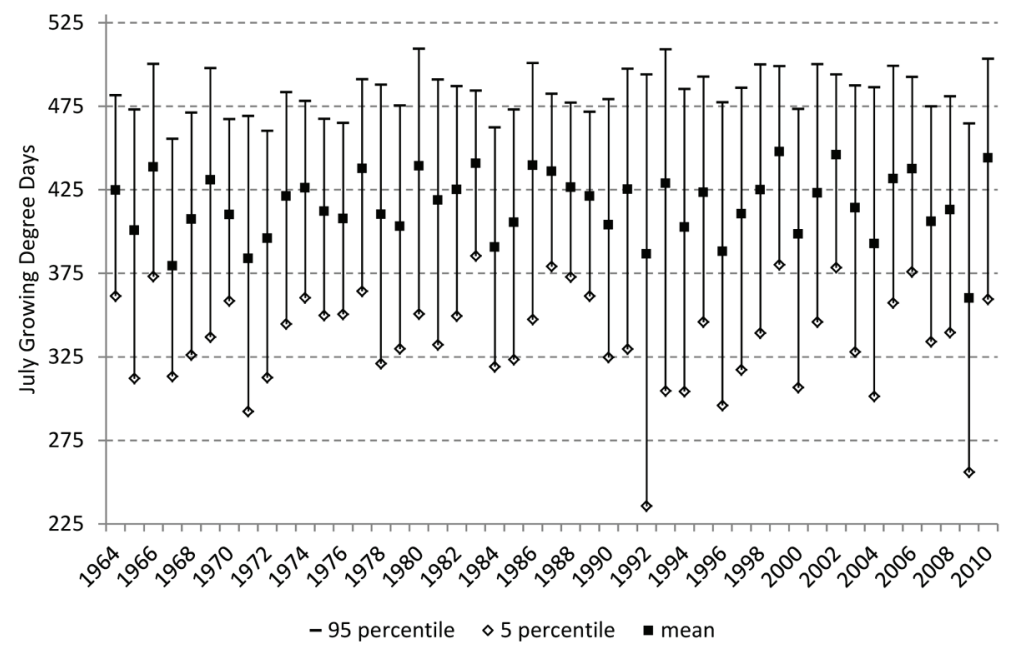

B

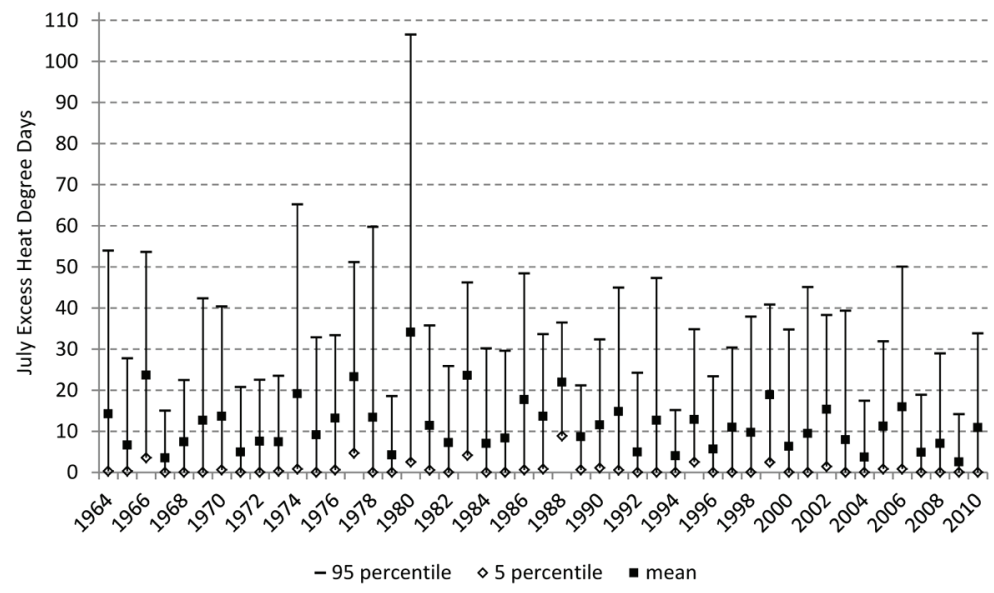

C

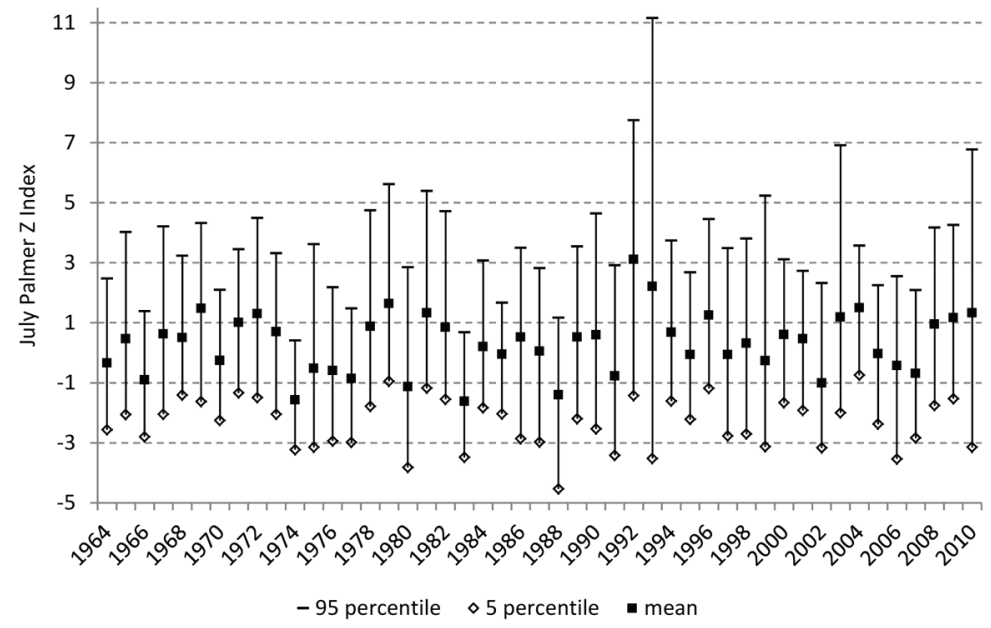

Figure 2. Level and variability of weather variables across weather stations in the month of July. Variability is represented by spread between 5th and 95th percentiles. Panel A: growing degree days $\left({ }^{\circ} \mathrm{C}\right)$ weather index; Panel B: excess heat degree days $\left({ }^{\circ} \mathrm{C}\right)$ weather index; Panel C: Palmer Z soil moisture index. For each county, data are from the weather station nearest to the geographic center of the county, as extracted from the U.S. Historical Climatology Network of 1218 weather stations in the 48 contiguous states. Information on temperature degree days is provided in Materials and Methods. Water stress is proxied by the Palmer Z index, which measures the departure from normal of the moisture climate for that month. A value of 0 is to be expected, -2 or less represents drought conditions, and +5 or more represents flood conditions. 


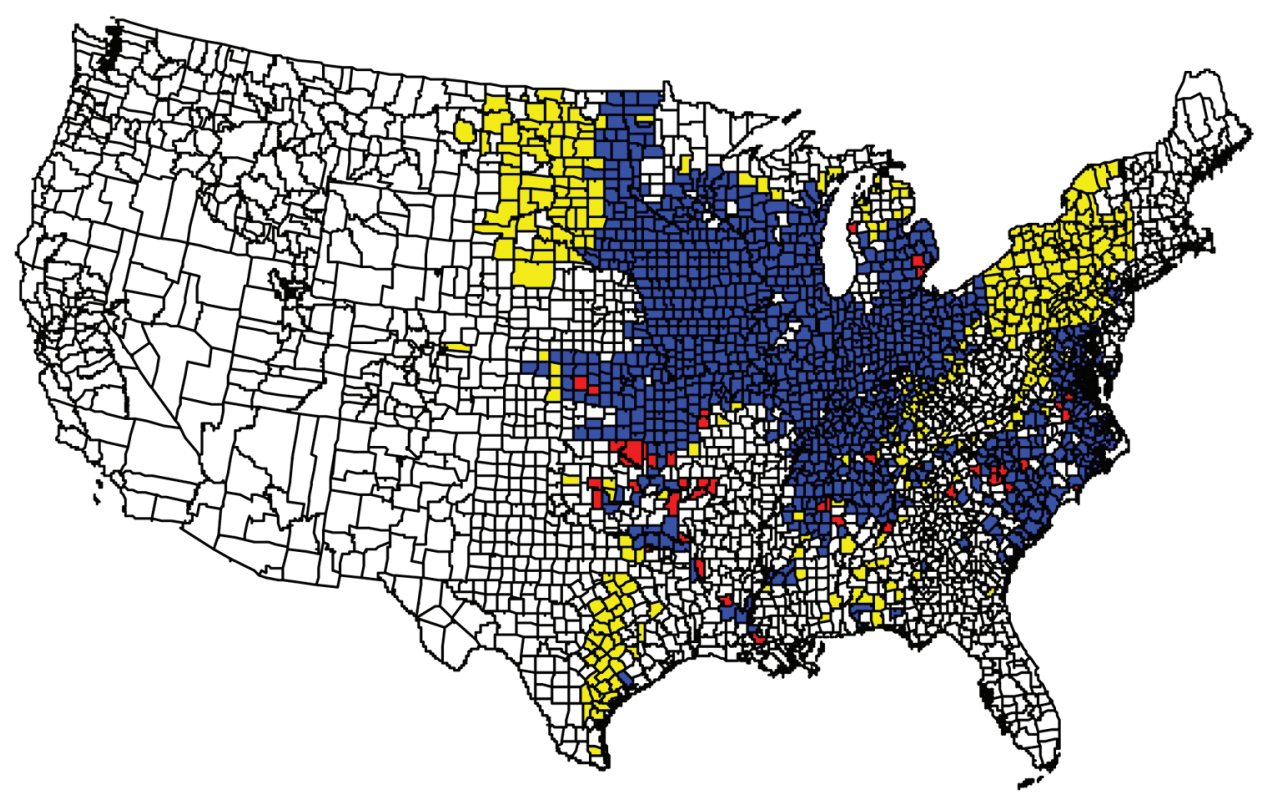

Figure 3. Counties included in the sample: yellow coloring indicate maize only (331 counties), red indicates soybean only (44 counties), and blue indicates both maize and soybean (1019 counties). Counties included were those where (i) $<10 \%$ of harvested cropland was irrigated (2002 U.S. Census of Agriculture [USDA-NASS, 2004]), (ii) data were available for at least two thirds of the pre-genetically engineered (GE) years and two thirds of the post-GE years (e.g., pre- and post-1996 for soybean), and (iii) complete Palmer's Z index time series were available.

$=1,2, \ldots, 1350$ (for maize) and $i=1,2, \ldots, 1063$ (for soybean) denotes counties. The regression model for the alternative slope specification is reported in Eq. [2]. For all models, the betas are the parameters to be estimated. There are a variety of econometric procedures that could be used with panel data such as ours (Wooldridge, 2001). The results that we report rely on the fixed-effects model, which amounts to assuming that systematic heterogeneity between the cross-sectional units of the panel can be captured by differences in the (county-specific) constant terms $\alpha_{i}$ in Eq. [1] and Eq. [2]. Thus, the fixed-effects model allows us to account in an efficient way for factors, such as soil quality, that are known to be important determinants of agricultural productivity. Because such factors can be assumed to be largely time invariant (at least for the time span of our sample), the fixed-effect estimation procedure removes the possible bias that typically arises when one omits relevant explanatory variables. Given the foregoing assumption, the error term $\varepsilon_{i, t}$ is then assumed to be identically and independently distributed such that standard OLS or maximum-likelihood (given normality) procedures can be readily applied to obtain consistent estimates of the parameters of interest (the betas).

\section{RESULTS AND DISCUSSION}

Complete estimation results are reported in the Supplemental Tables S1, S2, S3, and S4. The fit of all models as measure by $R^{2}$ is fairly good for both crops, ranging from 0.785 to 0.81 . Supplemental Table S1 also reports the Ahrens-Pincus unbalancedness measure (Ahrens and Pincus, 1981). Recall that, as discussed earlier, some counties included in our sample do not have observation for the entire 47-yr period, that is, we have an unbalanced panel data set. The fact that the Ahrens-Pincus measure exceeds
0.99 in all cases indicates that the degree of unbalancedness in our sample is extremely low.

The following null hypotheses were tested by suitable parametric restrictions: no technological trend effects (i.e., $\beta_{T}=\beta_{R T}=0$ ), no regional effects (i.e., $\beta_{R T}=\beta_{A R}=\beta_{A R T}$ $=0$ ), no $\mathrm{GE}$ adoption effects (i.e., $\beta_{A}=\beta_{A R}=\beta_{A T}=\beta_{A R T}$ $=0$ ), no weather impacts (i.e., $\beta_{\mathrm{Gm}}=\beta_{E m}=\beta_{Z m}=\beta_{Z Z m}=$ 0 ) for each relevant month $m$, and no fertilizer effects (i.e., $\left.\beta_{N}=0\right)$. As can be evinced by comparing the reported likelihood ratio statistics with the appropriate critical values of the $\chi^{2}$ distribution (reported in Supplemental Table S4), all of these hypotheses were rejected decisively at the $1 \%$ significance level, lending further support for the model specification adopted in this study.

The models of Eq. [1] and [2] performed similarly in terms of fit, the signs of estimated coefficients accord with intuition and theory, and virtually all coefficients of interest are statistically significant (1\% level). Before considering the estimated responses of yield to trend, region, and GE variety adoption that are the paper's main focus, some discussion concerning the estimated responses to $\mathrm{N}$ fertilization and weather variables may be in order.

Weather effects are similar across the models (see Supplemental Tables S2 and S3). They are generally both consistent with intuition and strongly significant. For maize in May, June, and July there is a positive response to growing degree days. In May, June, July, and August there is a very strong negative response to excess heat. The loss per degree of overheating is in the order of 30 times larger than the loss per degree decline in growing degrees, 
consistent with findings in Schlenker and Roberts (2006). This finding suggests vulnerability of yields to any climate shift unless genetics and management practices can adapt promptly. For maize, in May and September yield is decreasing and concave in the Palmer index indicating that a dry spring and a dry harvest are optimal when all else is equal. Across June, July and August, Palmer indices have positive linear and negative quadratic terms with maximum values toward the moist side. The inference is that a dry early summer and more moist late summer are optimal. This is consistent with the known importance of ample moisture around silking, which typically occurs in mid July across the study region (Bruce et al., 2002).

For soybeans, all months show a positive response to growing degree days. In all months there is a stronger negative response to excess heat where the loss per degree of overheating is typically five or more times larger than the loss per degree decline in growing degrees. For May the Palmer $\mathrm{Z}$ index linear and quadratic effects are both negative where a wet spring can delay planting or harm an emerging crop and so reduce yield, for example, Egli and Cornelius (2009). For July, August, and September, Palmer indices have positive linear and negative quadratic terms, as with maize during the mid and late season. Ample soil moisture during these months enhances yield.

Given that farmers presumably choose fertilization levels as part of their profit maximization program, estimated response to fertilization rates are best understood with reference to the standard optimization rule that requires marginal product to equal $\mathrm{N}$ price divided by corn price (Sawyer et al., 2006). To illustrate, the ratio of $\mathrm{N}$ price $\left(\$ \mathrm{~kg}^{-1}\right)$ to the corn price $\left(\$ \mathrm{t}^{-1}\right)$, the latter measured as the average price received by farmers in Illinois, over the period 1965 through 2010 has averaged at about 0.005 (using $\mathrm{CH}_{4} \mathrm{~N}_{2} \mathrm{O}$ prices for $\mathrm{N}$ ) and 0.007 (using anhydrous $\mathrm{NH}_{3}$ [ammonia] prices for $\mathrm{N}$ ), which are quite close to the estimated marginal effect of fertilizer on yield of 0.007 to $0.008 \mathrm{t} \mathrm{kg}^{-1}$ reported in Supplemental Tables S2 and S3. The estimated N response for soybeans is smaller although still significant. It is typically about one half that for maize. The difference in magnitude is in the direction to be expected, because average annual soybean prices have been at least twice as large as those of maize over most of the period considered.

Turning to the main concerns of this paper, the maize models' marginal effects with respect to trend and adoption are reported in Table 1, in which $\hat{y}_{i, t}$ indicates predicted value from the estimated models. For the shift model of Eq. [1], the estimated trend effect is $0.085 \mathrm{t}$ $\mathrm{ha}^{-1} \mathrm{yr}^{-1}$ in the CCB and $0.077 \mathrm{t} \mathrm{ha}^{-1} \mathrm{yr}^{-1}$ elsewhere; the GE adoption effect is predicted to increase yields (on full adoption) by $1.304 \mathrm{t} \mathrm{ha}^{-1}$ in the CCB and by 0.596 $\mathrm{t} \mathrm{ha}^{-1}$ elsewhere. Thus, the estimated GE impact is large (and stronger in the CCB). For instance, the GE adoption
Table 1. Estimated trend and genetically engineered (GE) adoption effects: U.S. maize in the Central Corn Belt (CCB) and outside the Central Corn Belt (non-CCB). Adoption shift model allows estimated yield level to adjust up or down with shift in proportion to GE adoption rate. Adoption slope model allows for a change in trend yield growth in proportion to GE adoption rate.

\begin{tabular}{lcc}
\hline \multicolumn{1}{c}{ Model } & $\begin{array}{c}\text { Yield response to } \\
\text { trend }^{\dagger}\end{array}$ & $\begin{array}{c}\text { Yield response to } \\
\text { adoption rate }\end{array}$ \\
\hline Adoption shift model & 0.0849 & 1.3040 \\
CCB & $(0.0010)^{\S}$ & $(0.0504)$ \\
Non-CCB & 0.0771 & 0.5955 \\
& $(0.0006)$ & $(0.0277)$ \\
Adoption slope model & & \\
CCB & $0.0926+0.0727 A_{[], t}$ & $0.0727\left(T_{t}-33\right)$ \\
& $(0.0009)(0.0038)$ & $(0.0038)$ \\
Non-CCB & $0.0802+0.0430 A_{[], t}$ & $0.0430\left(T_{t}-33\right)$ \\
& $(0.0006)(0.0022)$ & $(0.0022)$ \\
\hline
\end{tabular}

†Yield response to trend, $\partial \hat{y}_{i t} / \partial T_{t}$, represents the estimated annual yield increase due to underlying trend $\left(\mathrm{t} \mathrm{ha}^{-1} \mathrm{yr}^{-1}\right)$.

$\neq$ Field response to adoption rate, $\partial \hat{y}_{i, t} / \partial A_{[i], t}$, represents the estimated impact of full GE adoption on yield ( $\left.\mathrm{ha}^{-1}\right)$.

§Standard errors are reported in parentheses. See Supplemental Tables S2 and S3 for full estimation results.

shift in the CCB is equivalent to the productivity gains of about $15 \mathrm{yr}$ of the underlying trend. For the slope model of Eq. [2], the baseline trend effect in the CCB is estimated at $0.093 \mathrm{tha}^{-1} \mathrm{yr}^{-1}$. This is augmented to $0.165 \mathrm{t} \mathrm{ha}^{-1} \mathrm{yr}^{-1}$ on complete GE adoption, increasing the pre-GE annual productivity gain by $78 \%$. Outside the CCB these effects are smaller but still of significant magnitude.

For soybean (Table 2), the shift model shows a trend yield gain of $0.031 \mathrm{t} \mathrm{ha}^{-1} \mathrm{yr}^{-1}$ in the CCB and $0.027 \mathrm{tha}^{-1}$ $\mathrm{yr}^{-1}$ elsewhere. As a percent of the average yields, these annual gains are almost as large as in maize. However, for soybeans GE varieties are estimated to decrease yields (by $0.072 \mathrm{t} \mathrm{ha}^{-1}$ in the CCB and by $0.105 \mathrm{t} \mathrm{ha}^{-1}$ elsewhere, on full adoption). These findings confirm the yield drag concerns about GE soybean varieties raised previously (Elmore et al., 2001; National Research Council, 2010). Similar results emerge from the slope model. The differences in yield response to GE adoption between maize and soybean may be related to the nature of the traits embedded in these crops. For maize, commercial GE varieties have been herbicide tolerant, insect resistant, or both (stacked traits). For soybean, GE varieties have been herbicide tolerant only. The presumption that insect-resistant traits are more conducive to yield increases is consistent with our results although our model is not capable of disentangling the possible separate effects of different GE traits. Further inquiry into this issue might require more detailed adoption data than are publicly available.

Which of the two models that we have presented should be preferred cannot be determined based on our analysis and available data. The nearly identical performance of the shift and slope models makes them virtually statistically 
Table 2. Estimated trend and genetically engineered (GE) adoption effects: U.S. soybean in the Central Corn Belt (CCB) and outside the Central Corn Belt (non-CCB). Adoption shift model allows estimated yield level to adjust up or down with shift in proportion to GE adoption rate. Adoption slope model allows for a change in trend yield growth in proportion to GE adoption rate.

\begin{tabular}{lcc}
\hline \multicolumn{1}{c}{ Model } & $\begin{array}{c}\text { Yield response to } \\
\text { trend }^{\dagger}\end{array}$ & $\begin{array}{c}\text { Yield response to } \\
\text { adoption rate }\end{array}$ \\
\hline $\begin{array}{l}\text { Adoption shift model } \\
\text { CCB }\end{array}$ & 0.0312 & -0.0721 \\
Non-CCB & $(0.0003)^{\S}$ & $(0.0122)$ \\
Adoption slope model & 0.0269 & -0.1049 \\
CCB & $(0.0002)$ & $(0.0079)$ \\
& $0.0300-0.0015 A_{[], t}$ & $-0.0015\left(T_{t}-32\right)$ \\
Non-CCB & $(0.0003)(0.0010)$ & $(0.0010)$ \\
& $0.0253-0.0033 A_{[[], t}$ & $-0.0033\left(T_{t}-32\right)$ \\
\hline
\end{tabular}

†Yield response to trend, $\partial \hat{y}_{i, t} \partial \partial T_{t}$, represents the estimated annual yield increase due to underlying trend $\left(\mathrm{t} \mathrm{ha} \mathrm{H}^{-1} \mathrm{yr}^{-1}\right)$.

₹Yield response to adoption rate, $\partial \hat{y}_{i, t} / \partial A_{[], t,}$, represents the estimated impact of full GE adoption on yield $\left(\mathrm{tha}^{-1}\right)$.

\$Standard errors are reported in parentheses. See Supplemental Tables S2 and S3 full estimation results.

indistinguishable. Although the Akaike information criterion (Sakamoto et al., 1986) that could be used in this case (note that the two models are not nested) would favor the shift model, the difference is small and it seems unwise to rely on this model selection procedure because the two models have distinctly different implications moving forward. In fact, the GE shift model presumes a onceoff impact (on full adoption) and, because GE adoption is by now almost complete (Fig. 1), the implied GE yield impact is already almost fully reflected in current yields; by contrast, the slope model entails a continuing yield impact of GE innovation. We do not believe that the data at hand can discriminate between these two alternatives and therefore we remain agnostic as to the preferred model. Nonetheless, the combined results from the two models can be very informative as to the possible range of likely future yield gains. This is illustrated in Fig. 4, which provides a brief side-by-side comparison of the two models' results. Specifically, Fig. 4 reports the estimated combined (trend plus GE effects) productivity gains in both the CCB and non-CCB over the next $20 \mathrm{yr}$. The two models predict expected yield gains in the range of 17.5 to $31.8 \%$ for maize (relative to the 2010 average yield) and between 16.4 and $19.6 \%$ for soybean.

\section{CONCLUSIONS}

Continued improvements in agricultural productivity are critical to pursuing the goal of global food security when facing the challenges of a sizeable expected global population growth, climate uncertainties, environmental stress and land degradation, and the expansion of land used for nonfood production (Tilman et al., 2011; Foley et
A

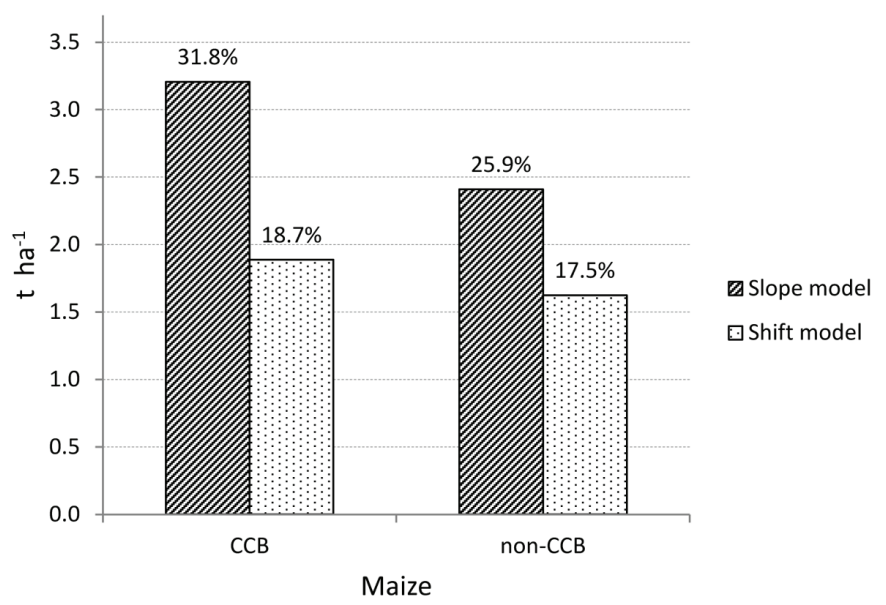

B

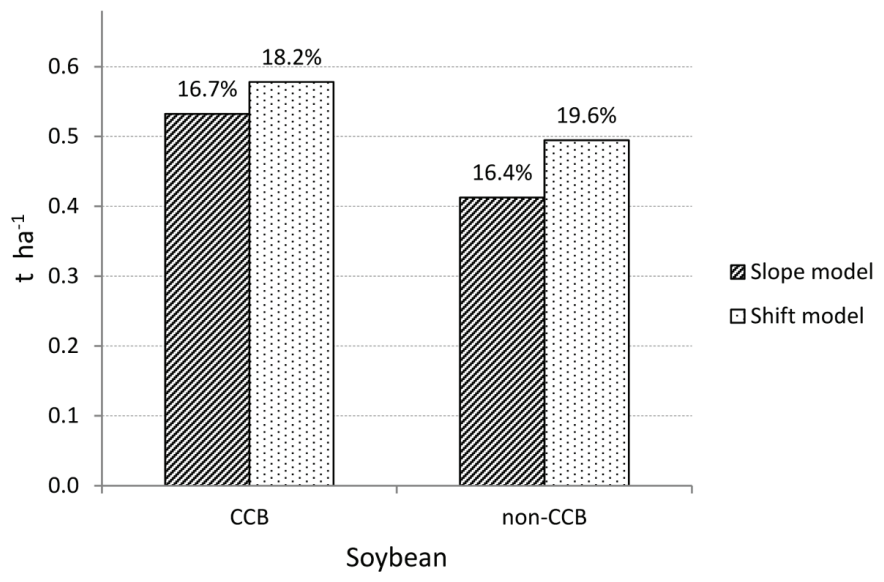

Figure 4. Estimated 20-yr yield gains (2011 through 2030) due to total crop improvement (t ha ${ }^{-1}$ and percent of 2010 average yield) in the Central Corn Belt (CCB) and non-CCB regions. Central Corn Belt refers to counties studied that are in lowa, Illinois, and Indiana. Non-CCB refers to counties studied that are not in these three states. Panel A: maize; panel B: soybean. Estimates combine trend and genetically engineered (GE) adoption effects reported in Tables 1 and 2. Projections assume full adoption of GE varieties by 2030 .

al., 2011). In particular, sustaining and possibly improving crop yield growth rates is essential to overcome the constraints on the available arable land. As in the past, such productivity improvements will need to rely on sustained contributions from research and innovation (Fischer and Edmeades, 2010). Biotechnology, including GE varieties, has much to offer in this setting. Just how much one should expect is an unresolved question. Yield gains are due to complex processes that include genetic improvement of plant varieties, interaction with a host of environmental factors, technical innovations in agricultural practices, and the impact of changing policy and market conditions. As such, realized yield gains have been gradual, and the history of past successes is arguably very informative on 
prospects for future yield gains. With that in mind, we have undertaken a detailed study of realized yields for the two major crops impacted by GE variety adoption (maize and soybean) in the United States, the country that has embraced the GE technology most enthusiastically. The goal has been to isolate the impact of the GE innovation per se from other determinants of realized yields.

We submit four main findings. First, for both crops the underlying yield growth rate has been strongest inside the CCB. Second, GE trait adoption has had a strong positive impact on maize yield. Third, the GE yield impact for maize has been strongest inside the CCB. Fourth, for soybean GE adoption has not increased yields, displaying instead a small yield drag effect. The analysis also highlights the magnitude of productivity gains due to overall crop improvement. Whereas the estimated total yield effects are large (Fig. 4), the fact that the specific contribution of GE variety adoption is positive for maize but absent or slightly negative for soybean confirms that a nuanced interpretation is needed. There are several reasons why GE varieties might be desirable from the farmers' perspectives, as discussed earlier, and their adoption might improve economic efficiency apart from their direct impact on yields. If the latter is the main element of interest, which is the case in the context of analyzing food security, what the GE technology can contribute is likely to depend on which traits are adopted.

Focusing on maize, for which the estimated specific contribution of GE varieties is positive and significant, we find that the most optimistic of our models predicts a 31.8\% total gain in maize yields over the 2011 through 2030 period in the CCB (and a $25.9 \%$ maize yields gain outside of the CCB), which is less than one third of the "doubling yields" target suggested as feasible in Edgerton (2009). Such differences are not trivial. To place these findings in context, note that the average maize yield in 2010 was $10.07 \mathrm{t} \mathrm{ha}^{-1}$ in the CCB region and $8.94 \mathrm{tha}^{-1}$ in the non-CCB region. When applied to these base yields, the most optimistic of our models would predict 2030 yields of $13.27 \mathrm{t} \mathrm{ha}^{-1}$ in the CCB region and $11.26 \mathrm{t} \mathrm{ha}^{-1}$ in the non-CCB region. With these yields, to achieve the same level of total maize production obtained under the "doubling yields" scenario and the 2010 harvested area would require an expansion of maize acreage of $51.7 \%$ in the CCB region and of $58.9 \%$ in the non-CCB region.

Whereas a considerable body of knowledge lends support to the methodology used in this study, it is apparent that unconditional forecasts of the impact of new technologies are problematic. As Nobel laureate Kenneth Arrow observes: "Any theory that purports to explain novelty, whether it deal with invention, innovation, or the emergence of new species of biota, is intrinsically difficult and paradoxical. How can you have a theory of the unexpected? If you can understand what novelties will emerge, they would not be novelties" (Arrow, 2012, p. 43). In our setting, it is of course possible that past yield trend may not fully predict the possible impacts of novel techniques, such as marker-assisted selection (Tester and Langridge, 2010). Also, progress with the thorny issues of abiotic stress (e.g., drought tolerance [Carena et al., 2009; Yang et al., 2010; Tollefson, 2011]), might lead to hitherto unanticipated productivity gains. The results presented here for U.S. maize and soybean, however, highlight the challenges inherent in the pursuit of yield improvements that significantly exceed the historical record of realized productivity gains.

\section{References}

Ahrens, H., and R. Pincus. 1981. On two measures of unbalancedness in a one-way model and their relation to efficiency. Biometric. J. 23:227-235. doi:10.1002/bimj.4710230302

Alston, J.M., J.M. Beddow, and P.G. Pardey. 2009. Agricultural research, productivity, and food prices in the long run. Science 325:1209-1210. doi:10.1126/science.1170451

Arrow, K. 2012. The economics of inventive activity over fifty years. In: J. Lerner and S. Stern, editors, The rate \& direction of inventive activity revisited. The Univ. of Chicago Press, Chicago, IL.

Bruce, W.B., G.O. Edmeades, and T.C. Barker. 2002. Molecular and physiological approaches to maize improvement for drought tolerance. J. Exp. Bot. 53(366):13-25. doi:10.1093/ jexbot/53.366.13

Carena, M.J., G. Bergman, N. Riveland, E. Eriksmoen, and M. Halvorson. 2009. Breeding maize for higher yield and quality under drought stress. Maydica 54:287-296.

Charles, D. 2002. Lords of the harvest: Biotech, big money, and the future of food. Perseus Publishing, Cambridge, MA.

Dominguez-Faus, R., S.E. Powers, J.G. Burken, and P.J. Alvarez. 2009. The water footprint of biofuel: A drink or drive issue. Environ. Sci. Technol. 43:3005-3010. doi:10.1021/es802162x

DuPont Company. 2012. 2011 DuPont data book. Dupont, Wilmington, DE. http://phx.corporate-ir.net/External.File ?item=UGFyZW50SUQ9NDYxMzAyfENoaWxkSUQ9N Dg5ODQ2fFR 5cGU9MQ==\&t=1 (accessed 30 May 2012).

E. I. du Pont de Nemours and Company. 2012. Dupont agriculture \& nutrition. Dupont, Wilmington, DE. http://www2. dupont.com/MLDP/en_US/assets/downloads/ag_nut.pdf (accessed 10 Feb. 2012).

Edgerton, M.D. 2009. Increasing crop productivity to meet global needs for feed, food, and fuel. Plant Physiol. 149:7-13. doi:10.1104/pp.108.130195

Edgerton, M.D., J. Fridgen, J.R. Anderson Jr., J. Ahlgrim, M. Criswell, P. Dhungana, T. Gocken, Z. Li, S. Mariappan, C.D. Pilcher, A. Rosielle, and S.B. Stark. 2012. Transgenic insect resistance traits increase corn yield and yield stability. Nat. Biotechnol. 30:493-496. doi:10.1038/nbt.2259

Egli, D.B., and P.L. Cornelius. 2009. A regional analysis of the response of soybean yield to planting date. Agron. J. 101:330335. doi:10.2134/agronj2008.0148

Elmore, R.W., F.W. Roeth, L.A. Nelson, C.A. Shapiro, R.N. Klein, S.Z. Knezevic, and A. Martin. 2001. Glyphosateresistant soybean cultivar yields compared with sister lines. Agron. J. 93:408-412. doi:10.2134/agronj2001.932408x

Environmental Systems Resource Institute (ESRI). 2011. ArcMap 9.3.1. ESRI, Redlands, CA.

Fedoroff, N.V., D.S. Battisti, R.N. Beachy, P.J.M. Cooper, D.A. 
Fischhoff, C.N. Hodges, V.C. Knauf, D. Lobell, B.J. Mazur, D. Molden, M.P. Reynolds, P.C. Ronald, M.W. Rosegrant, P.A. Sanchez, A. Vonshak, and J.-K. Zhu. 2010. Radically rethinking agriculture for the 21st Century. Science 327:833834. doi:10.1126/science.1186834

Fernandez-Cornejo, J. 2012. Adoption of genetically engineered crops in the U.S. USDA Economic Research Service, Washington, DC. http://www.ers.usda.gov/data-products/ adoption-of-genetically-engineered-crops-in-the-us.aspx (accessed 8 Oct. 2012).

Fischer, R.A., D. Byerlee, and G.O. Edmeades. 2009. Can technology deliver on the yield challenge to 2050? Expert Meeting on How to Feed the World in 2050. FAO, Econ. Social Dev. Dep., Rome. 24-26 June 2009. FAO, Rome, Italy.

Fischer, R.A., and G.O. Edmeades. 2010. Breeding and cereal yield progress. Crop Sci. 50:S85-S98. doi:10.2135/ cropsci2009.04.0225

FAO. 2011. The state of food insecurity in the world - How does international price volatility affect domestic economies and food security? FAO, Rome, Italy.

Foley, J.A., N. Ramankutty, K.A. Brauman, E.S. Cassidy, J.S. Gerber, M. Johnston, N.D. Mueller, C. O'Connell, D.K. Ray, P.C. West, C. Balzer, E.M. Bennett, S.R. Carpenter, J. Hill, C. Monfreda, S. Polasky, J. Rockström, J. Sheehan, S. Siebert, D. Tilman, and D.P.M. Zaks. 2011. Solutions for a cultivated planet. Nature 478:337-342. doi:10.1038/nature10452

Gardner, B.L. 2002. American agriculture in the twentieth century: How it flourished and what it cost. Harvard Univ. Press, Cambridge, MA.

Gómez-Barbero, M., J. Berbel, and E. Rodríguez-Cerezo. 2008. Bt corn in Spain - The performance of the EU's first GM crop. Nat. Biotechnol. 26:384-386. doi:10.1038/nbt0408-384

Griliches, Z. 1960. Hybrid corn and the economics of innovation. Science 132:275-280. doi:10.1126/science.132.3422.275

Gurian-Sherman, D. 2009. Failure to yield: Evaluating the performance of genetically engineered crops. Union of Concerned Scientists, Cambridge, MA.

Heim, R.R., Jr. 2002. A review of twentieth-century drought indices used in the United States. Bull. Am. Meteorol. Soc. 83:1149-1165.

Herdt, R.W., and R. Nelson. 2011. Biotechnology and agriculture: Current and emerging applications. In: C.A. Carter, G. Moschini, and I. Sheldon, editors, Genetically modified food and global welfare. Emerald Publishing, Scarborough, UK.

Hertel, T. 2011. The global supply and demand for agricultural land in 2050: A perfect storm in the making? Am. J. Agric. Econ. 93:259-275.

Huang, J., R. Hu, S. Rozelle, and C. Pray. 2005. Insect-resistant GM rice in farmers' fields: Assessing productivity and health effects in China. Science 308:688-690. doi:10.1126/ science. 1108972

Huang, J., R. Hu, S. Rozelle, and C. Pray. 2008. Genetically modified rice, yields, and pesticides: Assessing farm-level productivity effects in China. Econ. Dev. Cult. Change 56:241-263. doi:10.1086/522898

Hutchison, W.D., E.C. Burkness, P.D. Mitchell, R.D. Moon, T.W. Leslie, S.J. Fleischer, M. Abrahamson, K.L. Hamilton, K.L. Steffey, M.E. Gray, R.L. Hellmich, L.V. Kaster, T.E. Hunt, R.J. Wright, K. Pecinovsky, T.L. Rabaey, B.R. Flood, and E.S. Raun. 2010. Areawide suppression of European corn borer with $\mathrm{Bt}$ maize reaps savings to non-Bt maize growers. Science 330:222-225. doi:10.1126/science.1190242
James, C. 2011. Global status of commercialized biotech/GM crops: 2011. Brief no. 43. International Service for the Acquisition of Agri-biotech Applications (ISAAA), Metro Manila, Philippines.

Lobell, D.B., W. Schlenker, and J. Costa-Roberts. 2011. Climate trends and global crop production since 1980. Science 333:616-620. doi:10.1126/science.1204531

Lu, Y., K. Wu, Y. Jiang, Y. Guo, and N. Desneux. 2012. Widespread adoption of $\mathrm{Bt}$ cotton and insecticide decrease promotes biocontrol services. Nature 487:362-365. doi:10.1038/ nature11153

Ma, B.L., F. Meloche, and L. Wei. 2009. Agronomic assessment of Bt trait and seed or soil-applied insecticides on the control of corn rootworm and yield. Field Crops Res. 111:189-196. doi:10.1016/j.fcr.2008.12.006

Miller, H.I., and G. Conko. 2004. The Frankenfood myth - How protest and politics threaten the biotech revolution. Praeger Publishers, Westport, CT.

Monsanto Company. 2011. Form 10-K (Annual report pursuant to Section 13 or $15(\mathrm{~d})$ of the Securities Exchange Act of 1934). Monsanto Company, St. Louis, MO. http://www. monsanto.com/investors/Documents/Annual\%20Report/ Monsanto_2011_10-K.pdf (accessed 30 May 2012).

Monsanto Company. 2012. Who we are; United States. Monsanto Company, St. Louis, MO. http://www.monsanto.com/ whoweare/Pages/unitedstates.aspx (accessed 10 Feb. 2012).

Moschini, G. 2008. Biotechnology and the development of food markets: Retrospect and prospects. Eur. Rev. Agric. Econ. 35:331-355. doi:10.1093/erae/jbn014

Moschini, G. 2010. Competition issues in the seed industry and the role of intellectual property. Choices 25(2). Agricultural \& Applied Economics Association, Milwaukee, WI. http:// www.choicesmagazine.org/magazine/pdf/article_120.pdf (accessed 30 May 2012).

National Research Council. 2010. Impact of genetically engineered crops on farm sustainability in the United States. National Academies Press, Washington, DC.

Neild, R.E., and J.E. Newman. 1990. Growing season characteristics and requirements in the corn belt. National Corn Handbook, Climate and Weather, Purdue University Cooperative Extension Service, West Lafayette, IN.

Palmer, W.C. 1965. Meteorological drought. Research paper no. 45. Office of Climatology, U.S. Weather Bureau, U.S. Dep. of Commerce, Washington, DC.

Park, J.R., I. McFarlane, R.H. Phipps, and G. Ceddia. 2011. The role of transgenetic crops in sustainable development. Plant Biotechnol. J. 9:2-21. doi:10.1111/j.1467-7652.2010.00565.x

Qaim, M., and A. de Janvry. 2005. Bt and pesticide use in Argentina: Economic and environmental effects. Environ. Dev. Econ. 10:179-200. doi:10.1017/S1355770X04001883

Qaim, M., and D. Zilberman. 2003. Yield effects of genetically modified crops in developing countries. Science 299:900902. doi:10.1126/science.1080609

Runge, C.F., and B. Senauer. 2007. How biofuels could starve the poor. For. Aff. 86:41-53.

Sakamoto, Y., M. Ishiguro, and G. Kitagawa. 1986. Akaike information criterion statistics. Kluwer, Boston, MA.

Salvagiotti, F., K.G. Cassman, J.E. Specht, D.T. Walters, A. Weiss, and A. Dobermann. 2008. Nitrogen uptake, fixation and response to fertilizer $\mathrm{N}$ in soybeans: A review. Field Crops Res. 108:1-13. doi:10.1016/j.fcr.2008.03.001

Salvagiotti, F., J.E. Specht, K.G. Cassman, D.T. Walters, A. Weiss, 
and A. Dobermann. 2009. Growth and nitrogen fixation in high-yielding soybeans: Impacts of nitrogen fertilization. Agron. J. 101:958-970. doi:10.2134/agronj2008.0173x

Sawyer, J., E. Nafzinger, G. Randall, L. Bundy, G. Rehm, and B. Joern. 2006. Concepts and rationale for regional nitrogen rate guidelines for corn. PM 2015. Iowa State University Extension, Ames, IA.

Schlenker, W., and M.J. Roberts. 2006. Nonlinear effects of weather on corn yields. Rev. Agric. Econ. 28:391-398. doi:10.1111/j.1467-9353.2006.00304.x

Schlenker, W., and M.J. Roberts. 2009. Nonlinear temperature effects indicate severe damages to U.S. crop yields under climate change. Proc. Natl. Acad. Sci. USA 106:15594-15598. doi:10.1073/pnas.0906865106

Smil, V. 2004. Enriching the Earth: Fritz Haber, Carl Bosch, and the transformation of world food production. MIT Press, Cambridge, MA.

Tannura, M.A., S.H. Irwin, and D.L. Good. 2008. Weather, technology, and corn and soybean yields in the U.S. corn belt. Tech. Rep. 2008-01. Dep. Agric. Cons. Econ., Univ. of Illinois, Urbana-Champaign, IL.

Tester, M., and P. Langridge. 2010. Breeding technologies to increase crop production in a changing world. Science 327:818-822. doi:10.1126/science. 1183700

Tilman, D., C. Balzer, J. Hill, and B.L. Befort. 2011. Global food demand and the sustainable intensification of agriculture. Proc. Natl. Acad. Sci. USA 108:20260-20264. doi:10.1073/ pnas.1116437108

Tilman, D., R. Socolow, J.A. Foley, J. Hill, E. Larson, L. Lynd, S. Pacala, J. Reilly, T. Searchinger, C. Somerville, and R. Williams. 2009. Beneficial biofuels - The food, energy, and environment trilemma. Science 325:270-271. doi:10.1126/ science. 1177970

Thompson, L.M. 1969. Weather and technology in the production of corn in the U.S. corn belt. Agron. J. 61:453-456. doi:10.2134/agronj1969.00021962006100030037x
Thompson, L.M. 1975. Weather variability, climate change, and grain production. Science 188:535-541. doi:10.1126/ science.188.4188.535

Tollefson, J. 2011. Drought-tolerant maize gets U.S. debut. Nature 469:144. doi:10.1038/469144a

United Nations. 2011. World population prospects: The 2010 revision. United Nations, New York, NY.

USDA Economic Research Service. 2011a. Adoption of genetically engineered crops in the U.S. USDA, Economic Research Service, Washington, DC. http://www.ers.usda.gov/dataproducts/adoption-of-genetically-engineered-crops-inthe-us.aspx (accessed 15 June 2011).

USDA Economic Research Service. 2011b. Fertilizer use and price. USDA, Economic Research Service, Washington, DC. http://www.ers.usda.gov/data-products/fertilizer-use-andprice.aspx (accessed 15 June 2011).

USDA National Agricultural Statistics Service (USDA-NASS). 2004. Census of agriculture, 2002. Chapter 2, various states. USDA-NASS, Washington, DC. http://www.agcensus.usda. gov/Publications/2002/index.php (accessed 15 June 2011).

USDA National Agricultural Statistics Service (USDA-NASS). 2012. Quick stats database. USDA-NASS, Washington, DC. http:// www.nass.usda.gov/Quick_Stats/ (accessed 19 Dec. 2012).

Wooldridge, J.M. 2001. Econometric analysis of cross section and panel data. MIT Press, Cambridge, MA.

Wright, B.D. 2011. The economics of grain price volatility. Appl. Econ. Persp. Pol. 33:32-58. doi:10.1093/aepp/ppq033

Wu, K.-M., Y.-H. Lu, H.-Q. Feng, Y.-Y. Jiang, and J.-Z. Zhao. 2008. Suppression of cotton bollworm in multiple crops in China in areas with Bt toxin-containing cotton. Science 321:1676-1678. doi:10.1126/science.1160550

Yang, S.-J., B. Vanderbeld, J.-X. Wan, and Y.-F. Huang. 2010. Narrowing down the targets: Towards successful genetic engineering of drought-tolerant crops. Molec. Plant 3:469490. doi:10.1093/mp/ssq016 